\title{
How good are the simulations of tropical SST-rainfall relationship by IPCC AR4 atmospheric and coupled models?
}

\author{
K Rajendran $^{1, *}$, Ravi S Nanjundiah ${ }^{2,3}$, Sulochana Gadgil ${ }^{3}$ and J SRinivasan ${ }^{2,3}$ \\ ${ }^{1}$ Centre for Mathematical Modelling and Computer Simulation, Bangalore 560 037, India. \\ ${ }^{2}$ Divecha Center for Climate Change, Indian Institute of Science, Bangalore 560 012, India. \\ ${ }^{3}$ Centre for Atmospheric and Oceanic Sciences, Indian Institute of Science, Bangalore 560 012, India. \\ ${ }^{*}$ Corresponding author. e-mail: rajendrank@hotmail.com
}

\begin{abstract}
The failure of atmospheric general circulation models (AGCMs) forced by prescribed SST to simulate and predict the interannual variability of Indian/Asian monsoon has been widely attributed to their inability to reproduce the actual sea surface temperature (SST)-rainfall relationship in the warm Indo-Pacific oceans. This assessment is based on a comparison of the observed and simulated correlation between the rainfall and local SST. However, the observed SSTconvection/rainfall relationship is nonlinear and for this a linear measure such as the correlation is not an appropriate measure. We show that the SSTrainfall relationship simulated by atmospheric and coupled general circulation models in IPCC AR4 is nonlinear, as observed, and realistic over the tropical West Pacific (WPO) and the Indian Ocean (IO). The SST-rainfall pattern simulated by the coupled versions of these models is rather similar to that from the corresponding atmospheric one, except for a shift of the entire pattern to colder/warmer SSTs when there is a cold/warm bias in the coupled version.
\end{abstract}

\section{Introduction}

The interannual variation of the Asian/Indian summer monsoon is linked with ENSO (Sikka 1980; Rasmusson and Carpenter 1983), and hence to the sea surface temperature (SST) anomalies over the central and eastern equatorial Pacific Ocean. The SST anomalies of the western Pacific and Indian Ocean warm pools have also been considered to be important for monsoon variability (Nitta 1987; Shen and Lau 1995; Lau et al 2000; Kawamura et al 2001). Yet, the skill of the atmospheric general circulation models (AGCMs) forced by observed SST, in simulating the interannual variability of the Asian/Indian summer monsoon rainfall, is poor
(Sperber and Palmer 1996; Gadgil and Sajani 1998; Kang et al 2002; Kang and Shukla 2005).

Over warm parts of the tropical oceans such as the western Pacific Ocean, Bay of Bengal and South China Sea, the correlation of the observed rainfall with the local SST is insignificant or negative (Wang et al 2005). However, in the CLIVARmonsoon Panel Project simulations of June-JulyAugust (JJA) 1997-1998 by AGCMs forced with prescribed SST, the SST-rainfall correlations over these regions were positive (Wang et al 2004), and in the forced simulations of NCAR's AGCM, these were positive/insignificant (Trenberth and Shea 2005). It is believed that over such regions, the SST anomalies are driven at least in part by surface

Keywords. SST; rainfall; AGCMs; CGCMs; local and remote impacts. 
fluxes and wind stress (e.g., Lau and Nath 2000; $\mathrm{Wu}$ and Kirtman 2005), and hence it is important to incorporate air-sea coupling in the models to simulate the SST-rainfall relationship. It has been suggested that forced AGCMs successfully capture interannual variability over regions such as the tropical eastern and central Pacific, where oceanic processes cause SST anomalies, with surface heat fluxes having a damping effect (Kang et al 2001). Over other regions, their performance is less satisfactory (Kumar and Hoerling 1998).

Wang et al (2005) attributed the inability of AGCMs to simulate interannual variability of the summer monsoon rainfall to their inability in simulating the special nature of SST-rainfall relationship over regions such as the West Pacific Ocean, Bay of Bengal and South China Sea. Thus, assessment of how realistically the SST-rainfall relationship is simulated by atmospheric and coupled GCMs (CGCMs) is important. The importance of the nature of SST-rainfall relationship has also been brought out in a recent study (Johnson and Xie 2010) which showed that in a warming climate, despite the expected increase of SST, the fraction of the convectively active area over the tropical oceans is expected to change little.

In this study, we investigate the nature of the SST-rainfall relationship simulated by AGCMs and the coupled versions (CGCMs) of nine global climate models used in the Fourth Assessment Report of the Intergovernmental Panel on Climate Change (IPCC AR4), focussing on the simulation over the Indian Ocean, the west Pacific Ocean and the NINO3.4 region.

\section{Data and methodology}

We have examined two sets of experiments from the IPCC AR4 simulations. In the first set of experiments (20C3M), coupled GCMs are run under conditions similar to those of 20th century (Meehl et al 2007). In the second set of experiments, AGCMs are run as in Atmospheric Model Intercomparison Project (AMIP), with the observed SST specified as the boundary condition and initial conditions for the atmosphere specified only at the beginning of the multi-year run (Gates 1992). We have analysed runs for the 20-year period beginning in 1979 for AGCMs and the runs for the last 20 years for the CGCMs. Thus, any decadal changes or variability of the coupled model runs are ignored in this study.

Of the 13 IPCC AR4 GCMs for which both the coupled and uncoupled (forced) simulations are available, we selected nine GCMs with the highest pattern correlation coefficients between the simulated and observed JJA mean rainfall and mean
SST (for CGCMs) over the Indian Ocean and tropical West Pacific. The details of the climate models considered in this study, their acronyms, and horizontal and vertical resolutions are listed in table 1 . All the simulations were reduced to a $2.5^{\circ} \times 2.5^{\circ}$ grid for comparison with observations. The major components of these coupled models such as atmosphere, ocean, sea ice, land and vegetation are interactive, and the interaction of other components such as atmospheric chemistry, biogeochemistry and aerosols vary from model to model. Most of these CGCMs do not use surface flux corrections at the ocean-atmosphere interface, except MRI. Further details of these models and the simulations can be obtained from model documentation available at http://wwwpcmdi.llnl.gov/ipcc/model_documentation/ipcc_ model_ documentaion.php.

For observations, we have used monthly precipitation data from Global Precipitation Climatology Project $(\mathrm{GPCP})$ on $2.5^{\circ} \times 2.5^{\circ}$ grid for the period 1979-2007 (Adler et al 2003), and Hadley Centre Ice and SST (HadISST) data (Rayner et al 2003) on $2.5^{\circ} \times 2.5^{\circ}$ grid for $1979-2007$ period. We find that the the SST-rainfall relationship derived from Tropical Rainfall Measuring Mission (TRMM) Microwave Imager (TMI) SST is rather similar to that with HadISST. We, therefore, discuss here only the results based on HadISST. Monthly mean atmospheric fields for the corresponding period are taken from 40-year European Centre for Medium Range Weather Forecasts (ECMWF) Re-analysis (ERA-40) data (Uppala et al 2005).

For each of the three regions considered, the monthly SST and rainfall data for June, July and August of each year have been binned at intervals $0.25^{\circ} \mathrm{C}$ and $0.5 \mathrm{~mm} /$ day respectively. The SSTrainfall relationship is assessed by (i) scatter plots in which the number of points for each $0.25^{\circ} \mathrm{C}$ SST and $0.5 \mathrm{~mm} /$ day rainfall bin is indicated and (ii) the nature of the variation with SST of the mean rainfall, the standard deviation and the $90 \%$ percentile (obtained as the lower limit of the top $10 \%$ of rainfall values for each SST bin).

\section{Observed SST-rainfall relationship}

The nature of the observed relationship of the rainfall to local SST was first elucidated by Bjerknes (1969). He showed that at Canton island, while generally the monthly rainfall is less than $2 \mathrm{~mm} /$ day, the monthly rainfall was sustained at a high level, i.e., well over $6 \mathrm{~mm} /$ day for several months, when the SST was above $28^{\circ} \mathrm{C}$. Subsequent studies (Gadgil et al 1984; Graham and Barnett 1987; Waliser and Graham 1993; Zhang 


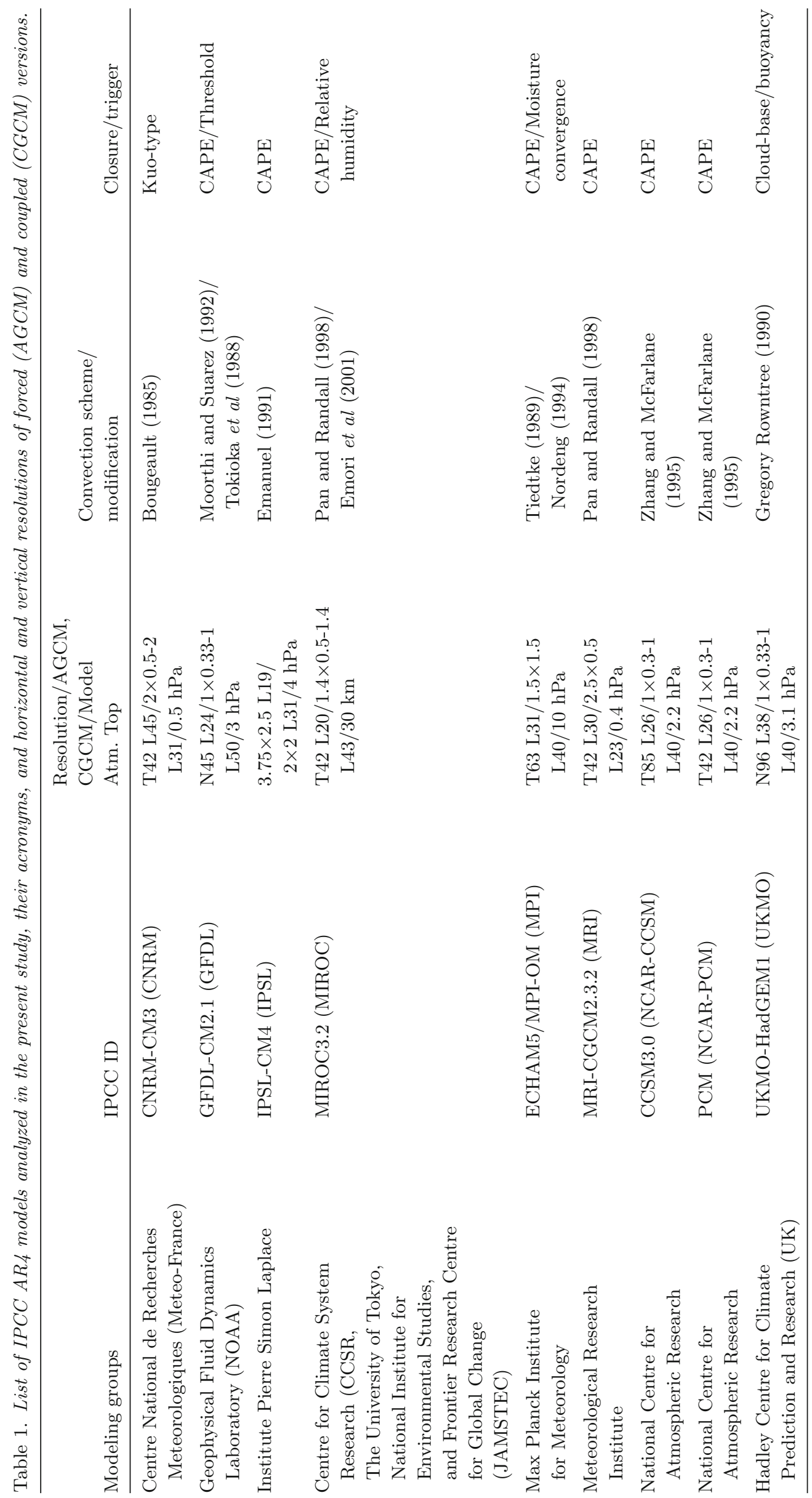


1993; Bony et al 1997) of the relationship between organized deep convection, based on satellite data, and local SST showed that the relationship is nonlinear and that there is a high propensity for tropical deep convection for SST above about $28^{\circ} \mathrm{C}$, which has been called the threshold, $T_{C}$, for organized convection. When the SST is above the threshold, the observed convection indices [such as the outgoing longwave radiation (OLR)] vary over a large range from almost no convection to intense deep convection.

We have considered the SST-rainfall relationship over three regions (figure 1a), viz., the Indian Ocean region (IO: $60^{\circ}-100^{\circ} \mathrm{E} ; 15^{\circ} \mathrm{S}-20^{\circ} \mathrm{N}$ ), the tropical West Pacific Ocean (WPO: $120^{\circ}-140^{\circ} \mathrm{E}$; $10^{\circ}-20^{\circ} \mathrm{N}$ ) and the Nino3.4 region (NINO34: $170^{\circ}-$ $\left.120^{\circ} \mathrm{W} ; 5^{\circ} \mathrm{S}-5^{\circ} \mathrm{N}\right)$. The $\mathrm{IO}$ region is chosen because besides being important for the Indian monsoon, it is characterized by a large range of variation of SST (including parts with SST well below the threshold as well as warm parts such as the Bay of Bengal and equatorial Indian Ocean) over which the relationship to the rainfall can be studied. The elucidation of the simulated SST-rainfall relationship over WPO is particularly important because, as pointed out by Wang et al (2004), the observed SST-rainfall correlation is negative over parts of the region (figure 1b). The NINO3.4 region has been chosen because the SST-rainfall relationship is known to be strong over that region.
The observed SST-rainfall relationship for IO is depicted in figure 2(a) as a scatter plot in which the number of points for each $0.25^{\circ} \mathrm{C}$ SST and $0.5 \mathrm{~mm} /$ day rainfall bin is indicated. The variation with SST of the mean rainfall, the standard deviation and the $90 \%$ percentile are shown in figure 2(b) and the percentage of grid points in each SST bin are shown in figure 2(c). The major features of the SST-convection relationship elucidated by the earlier studies are also seen in figure 2. The mean rainfall increases slowly with SST up to around $26.5^{\circ} \mathrm{C}$ [Palmen threshold for tropical cyclogenesis (Palmen 1948)] followed by a sharp increase of rainfall/moist convection with SST in the so-called critical range (Waliser and Graham 1993; Bhat et al 1996) up to about $28^{\circ} \mathrm{C}$ (figure $2 \mathrm{~b}$ ). Note that for SST higher than $T_{C}$, there is hardly any increase in the mean rainfall with SST. The most striking feature of the scatterplot of the frequency of grid points for the different SST and rainfall bins (figure 2a) is the large spread in the rainfall values for SST above about $28^{\circ} \mathrm{C}$. This is also reflected in the variation with SST of the standard deviation and the $90 \%$ percentile (figure $2 \mathrm{~b}$ ). The mode of the rainfall frequency distribution shifts from zero for SSTs below $T_{C}$ to $4-5$ $\mathrm{mm} /$ day above the threshold. It should be noted that there are very few grid points for SST beyond $30^{\circ} \mathrm{C}$ (figure 2c), the upper limit of SST (Waliser and Graham 1993; Ramanathan and Collins 1991; Pierrehumbert 1995).
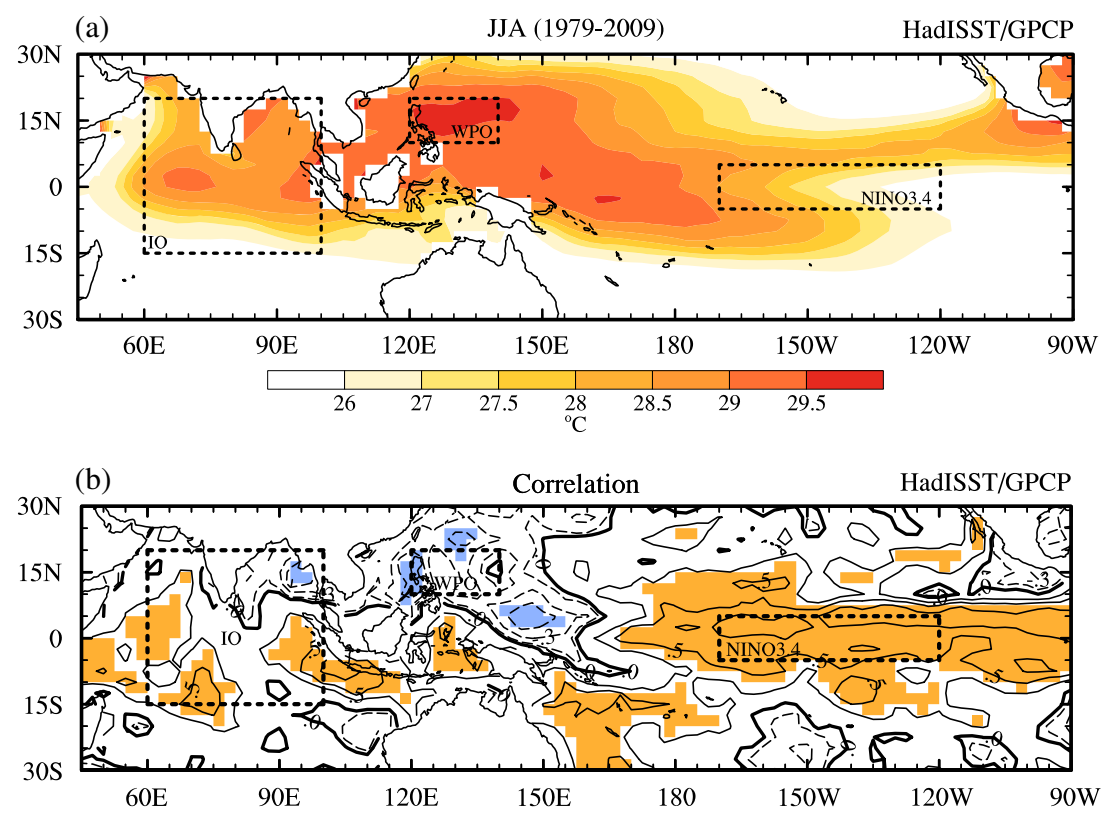

Figure 1. (a) Mean June-July-August (JJA) observed (HadISST) sea surface temperature and (b) the observed correlation between SST and rainfall (GPCP) for JJA during 1979-2009 (contours). Correlation significant at $90 \%$ level is shaded. The domains selected for analysis (denoted by respective abbreviation) is given in dashed rectangular boxes. 

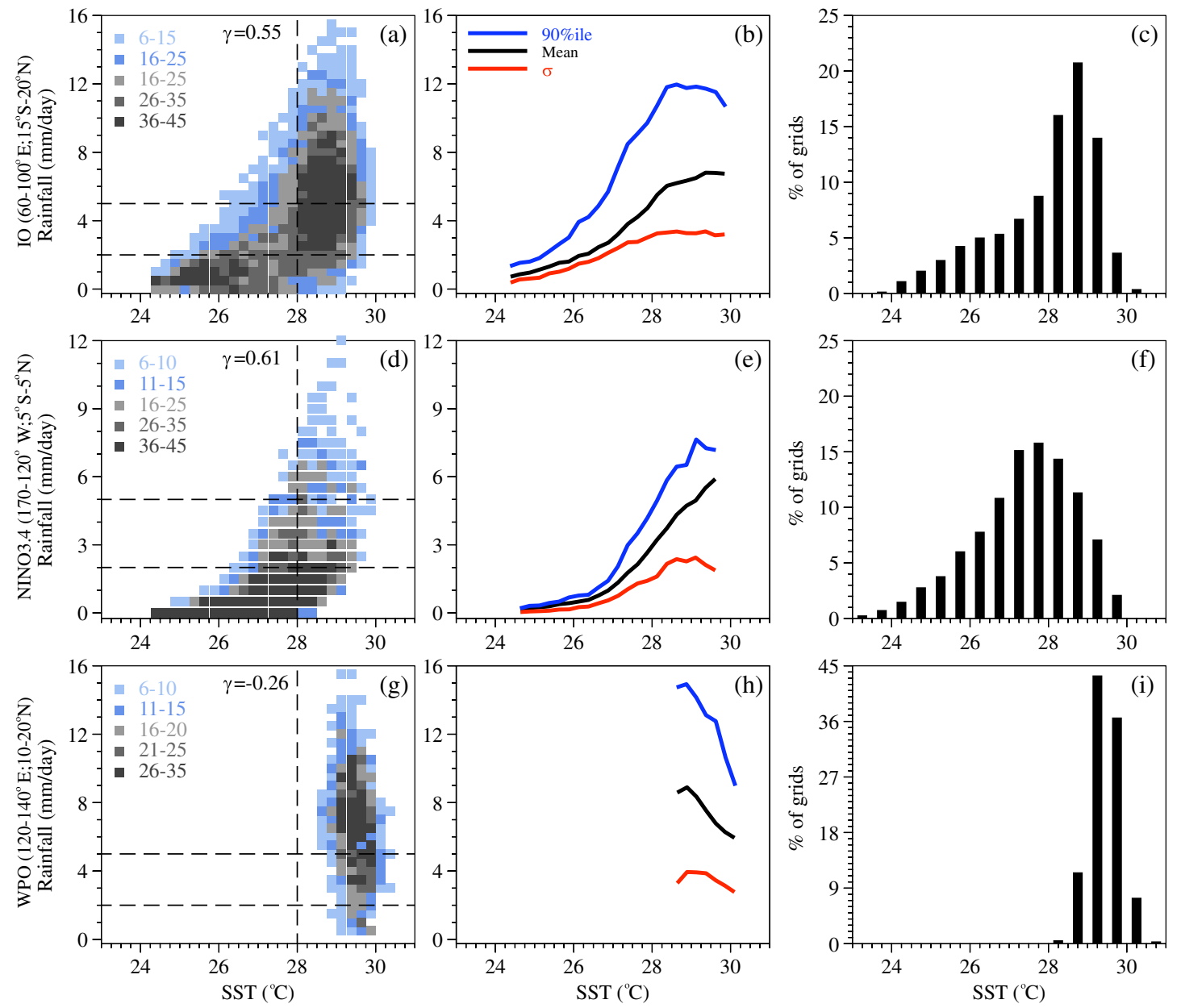

Figure 2. Observed relationship between rainfall and SST for June, July, August during 1979-2009 for the Indian Ocean (IO; $\mathbf{a}, \mathbf{b}, \mathbf{c})$, NINO3.4 (d, e, f), and West Pacific Ocean (WPO; $\mathbf{g}, \mathbf{h}, \mathbf{i}$ ). Scatter plots with the number of points for each $0.25^{\circ} \mathrm{C} \mathrm{SST}$ and $0.5 \mathrm{~mm} /$ day rainfall bin are shown in $(\mathbf{a}, \mathbf{d}, \mathbf{g})$, the variation with SST of the $90 \%$ percentile of rainfall (blue curve), mean rainfall (black curve) and the standard deviation of rainfall (red curve) in (b, e, h) respectively. Frequency distribution of SST in each $0.25^{\circ} \mathrm{C}$ SST bin for IO, NINO3.4 and WPO are shown in (c, $\mathbf{f}$ and $\left.\mathbf{i}\right)$ respectively.

The observed SST-rainfall relationship for NINO3.4 is shown in figure $2(\mathrm{~d}$ and $\mathrm{e})$ and WPO in figure $2(\mathrm{~g}$ and $\mathrm{h})$. It is seen that over NINO3.4, the mean as well as $90 \%$ percentile of the rainfall increases rapidly with SST from about $27^{\circ} \mathrm{C}$ and there is a strong relationship between SST and rainfall. The rainfall is highly correlated with SST for this region (correlation coefficient 0.61). Over WPO, the range of the variation of SST is rather small, being only about $1^{\circ} \mathrm{C}$. On the other hand, the variation of the rainfall for each SST bin is very large, indicating that the relationship between rainfall and the local SST is weak. The correlation between SST and rainfall for this region $(-0.26)$ is not significant even at $90 \%$. The mean rainfall over WPO decreases slowly with increasing SST, but given the small variation of SST and the large variation of the rainfall at each SST, the mean may not be particularly meaningful. The SST-rainfall relationship for the warm parts of IO such as the
Bay of Bengal (not shown) is similar to that over WPO.

The differences between the nature of the relationship over IO, WPO and NINO3.4 are a consequence of the differences in the range of the observed SST for these regions (figure 2c, $\mathrm{f}$ and i). For NINO3.4, about $65 \%$ of the points are characterized by SST lower than $28^{\circ} \mathrm{C}$. Thus, the SST variation is generally in the critical range in which the SST can have a large impact on rainfall. On the other hand, the observed SST of WPO is always above $28^{\circ} \mathrm{C}$, with almost $90 \%$ of points with SST higher than $29^{\circ} \mathrm{C}$. The rainfall variation is clearly not related to the SST variation over WPO. The decrease in organized convection/rainfall with SST after reaching maximum strength around $29 / 29.5^{\circ} \mathrm{C}$ is a manifestation of the association of the highest observed tropical SSTs with diminished convection (Bhat et al 1996). 
Thus, observations clearly show that the variation of the rainfall is related to the variation of the local SST when the SST varies over the critical range, i.e., with SST values ranging from below the threshold to above it. Furthermore, when the SST is always maintained above the threshold, the variation of SST appears to play no role in determining the variability of rainfall.

\section{Simulation of the SST-rainfall relationship}

The SST-rainfall relationship simulated by the atmospheric and coupled version of three representative models (GFDL, CNRM and IPSL), depicted as (i) scatter plots showing the frequency in each SST-rainfall bin and (ii) variation with SST of the mean and $90 \%$ percentile, for IO and WPO is shown in figures 3(a) and 3(b), respectively. Scatter plots of the rainfall simulated by the other AGCMs and CGCMs and SST (observed for AGCMs and simulated for CGCMs) for IO and WPO and all the models for Nino3.4 are shown in figures 4, 5 and 6 , respectively.

It is seen that, on the whole, the observed SSTrainfall relationship for these regions is well simulated by the AGCMs and CGCMs with realistic simulations of the patterns of the scatter plots (figures 3-6) as well as the variation with SST of the mean rainfall, and the $90 \%$ percentile (figure $3 \mathrm{a}$ and b). Thus, for IO and Nino3.4, as observed, (i) there is hardly any rainfall over cold regions (with SST less than about $26^{\circ} \mathrm{C}$ ), (ii) there is a high propensity of rainfall for SSTs above a threshold and (iii) over warm oceanic regions for which the SST is above the threshold, the variation of rainfall for a given SST is very large. The differences between the simulated patterns over the three regions arising from the differences in the

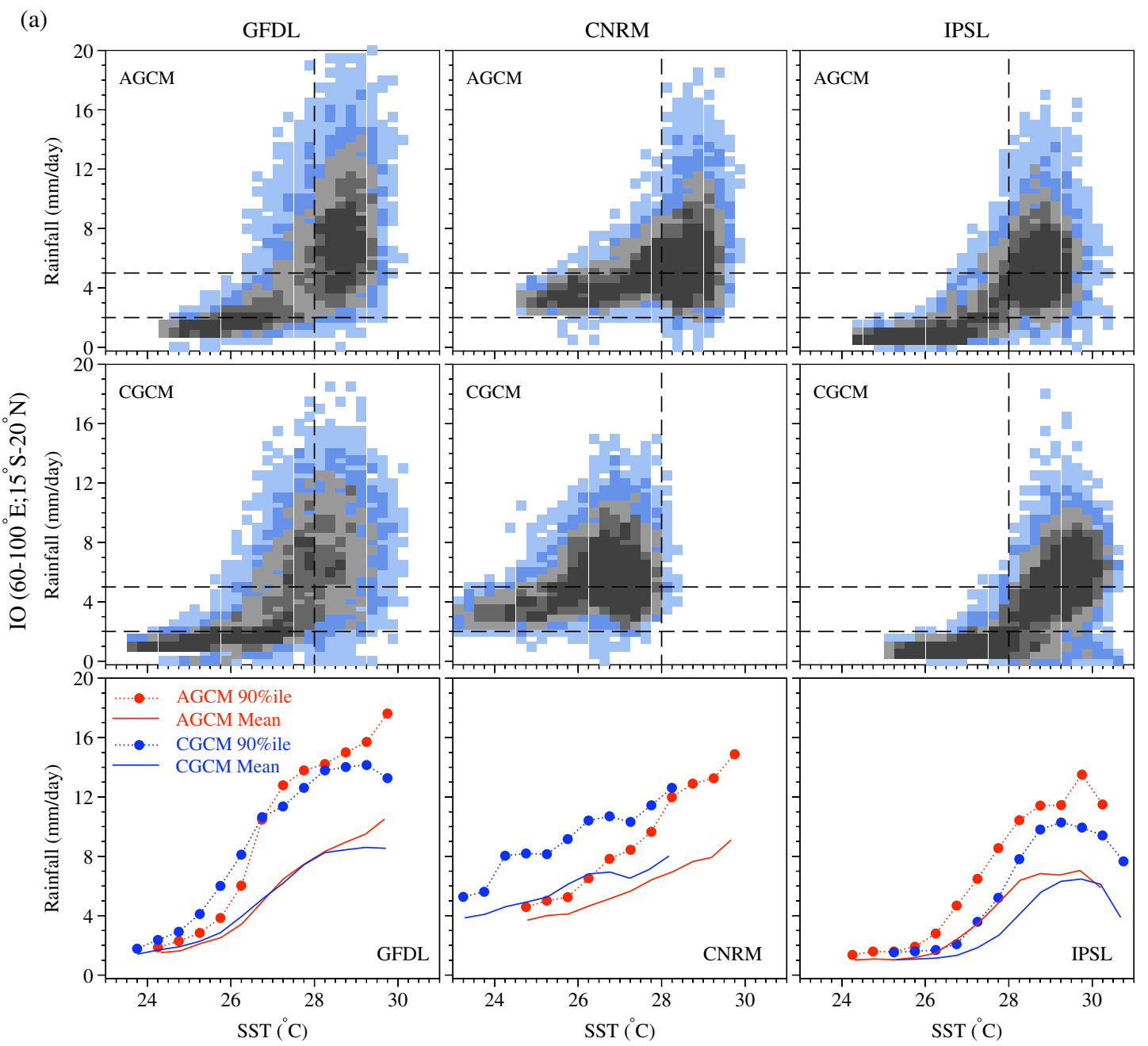

Figure 3(a). AGCM and CGCM (GFDL, CNRM and IPSL) simulated relationship between rainfall and SST for June, July, August over IO region. Scatter plots are shown with the number of points in each $0.25^{\circ} \mathrm{C}$ SST and $0.5 \mathrm{~mm} /$ day rainfall bin. The variation with SST of the $90 \%$ percentile of rainfall, and the mean rainfall for AGCM and CGCM are shown in the bottom panels. 


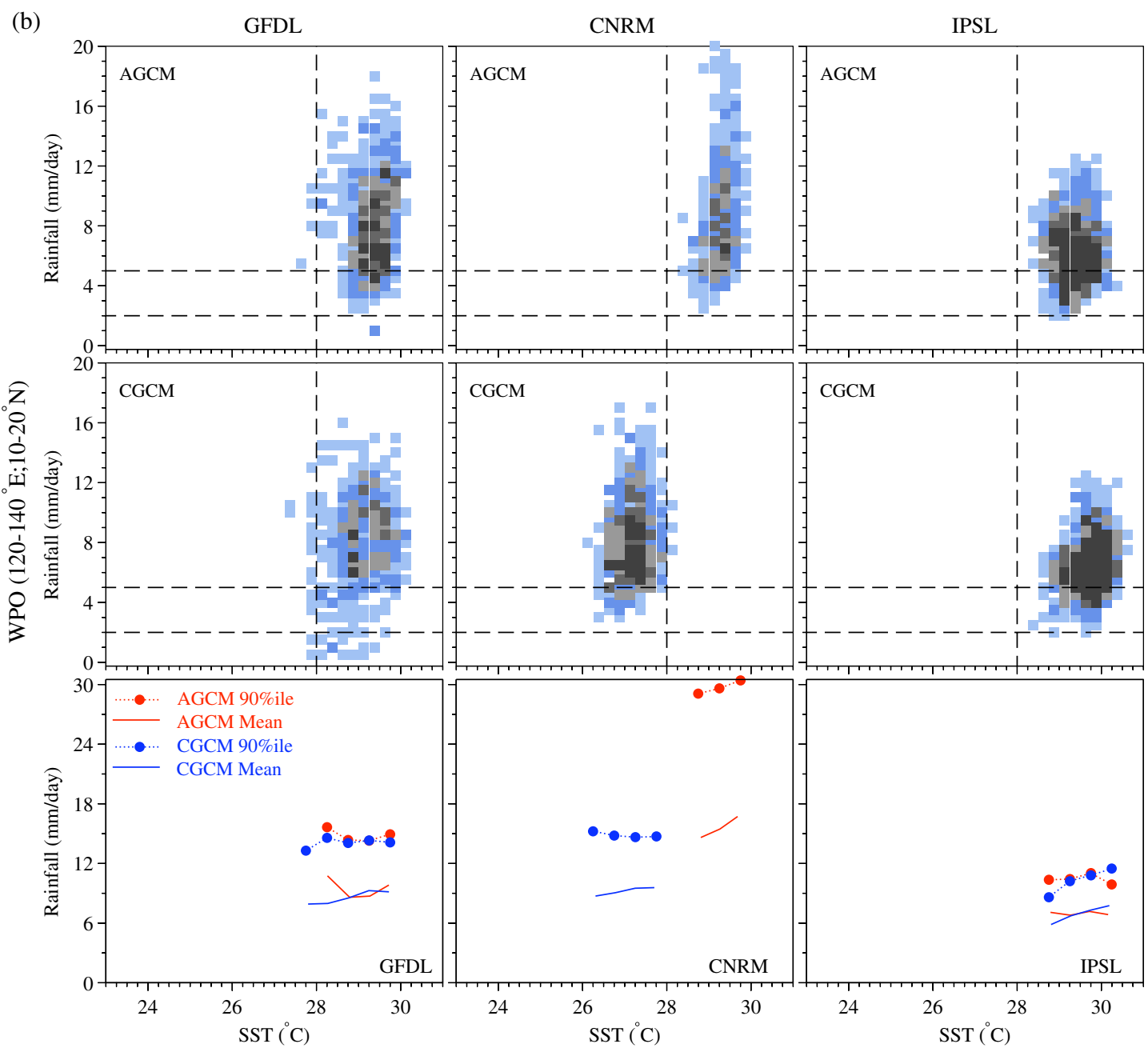

Figure 3(b). Same as figure 3(a), but for WPO region.

range of SST are also clearly seen. Since the SST of WPO is always above the threshold, as observed, there is a large variation in the rainfall for each value of SST.

It is important to note that the patterns simulated by the AGCM are rather similar to that by the corresponding CGCM even over regions, such as WPO, for which SST does not play a role in the variation of rainfall. However, the maximum rainfall simulated by an AGCM in some cases, is larger than that by the corresponding CGCM (e.g., CNRM; figure 3b), a feature also present in some other models (Nanjundiah et al 2005). Also, for many models, the CGCM simulates lower SSTs than observed. This cold bias is not large for a few of the CGCMs such as MIROC and MPI (figure 4). For some CGCMs, such as GFDL (figure $3 \mathrm{a}$ and $\mathrm{b}$ ), there is a shift in the mode of the simulated SST distribution from the observed towards colder SST by about $1^{\circ} \mathrm{C}$, and for some CGCMs such as CNRM (figure 3a and b), MRI, UKMO and NCAR (figure 4), there is a shift by about $2^{\circ} \mathrm{C}$. The SST-rainfall pattern simulated by the atmospheric versions of these models is rather similar to that from the corresponding CGCM, except for a shift to colder SSTs in the case of models with a cold bias such as the CGCM (figure 3a and b). Only the coupled version of the IPSL model simulates higher SSTs than observed, and in that case, the entire pattern shifts towards higher SSTs (figure $3 \mathrm{a}$ and $\mathrm{b}$ ).

As observed, the variation of the SST of WPO simulated by CGCMs is small. As in the case of IO, the simulated SSTs over WPO and NINO3.4 in several models are lower than observed and there is a shift in the SST-rainfall relationship (figures 3b, 5 and 6). Other than the shift, the patterns simulated by CGCM are rather similar to those by the corresponding AGCM.

The shift in the simulated SST-rainfall pattern for CGCMs towards lower or higher SST, depending on whether the simulated SST has a cold or a warm bias, is consistent with the results of several studies of the relationship of tropical 
convection and SST. The most important factor determining the variation of organized convection/ rainfall over the tropics is the convective available potential energy (CAPE) or the moist static stability (Bhat et al 1996; Williams and Renno 1993). The moist static stability depends on the local SST over tropical oceans. The observed lapse rate in the tropics is close to moist adiabatic lapse rate (Stone and Carlson 1979), which suggests an adjustment of the upper tropospheric temperatures to SST. Bhat et al's (1996) comparison of the relationship of CAPE with SST and the SST threshold, for two stations over the Atlantic and Indian Ocean, showed that there is a shift of the entire pattern towards colder SSTs over the relatively cooler Atlantic. Stowasser et al (2009) compared the run of the GFDL model for the present climate with the $4 \times \mathrm{CO}_{2}$ run and showed the nonlinear relationship between SST and evaporation; with higher SSTs, in the $4 \times \mathrm{CO}_{2}$ runs, the SST threshold for

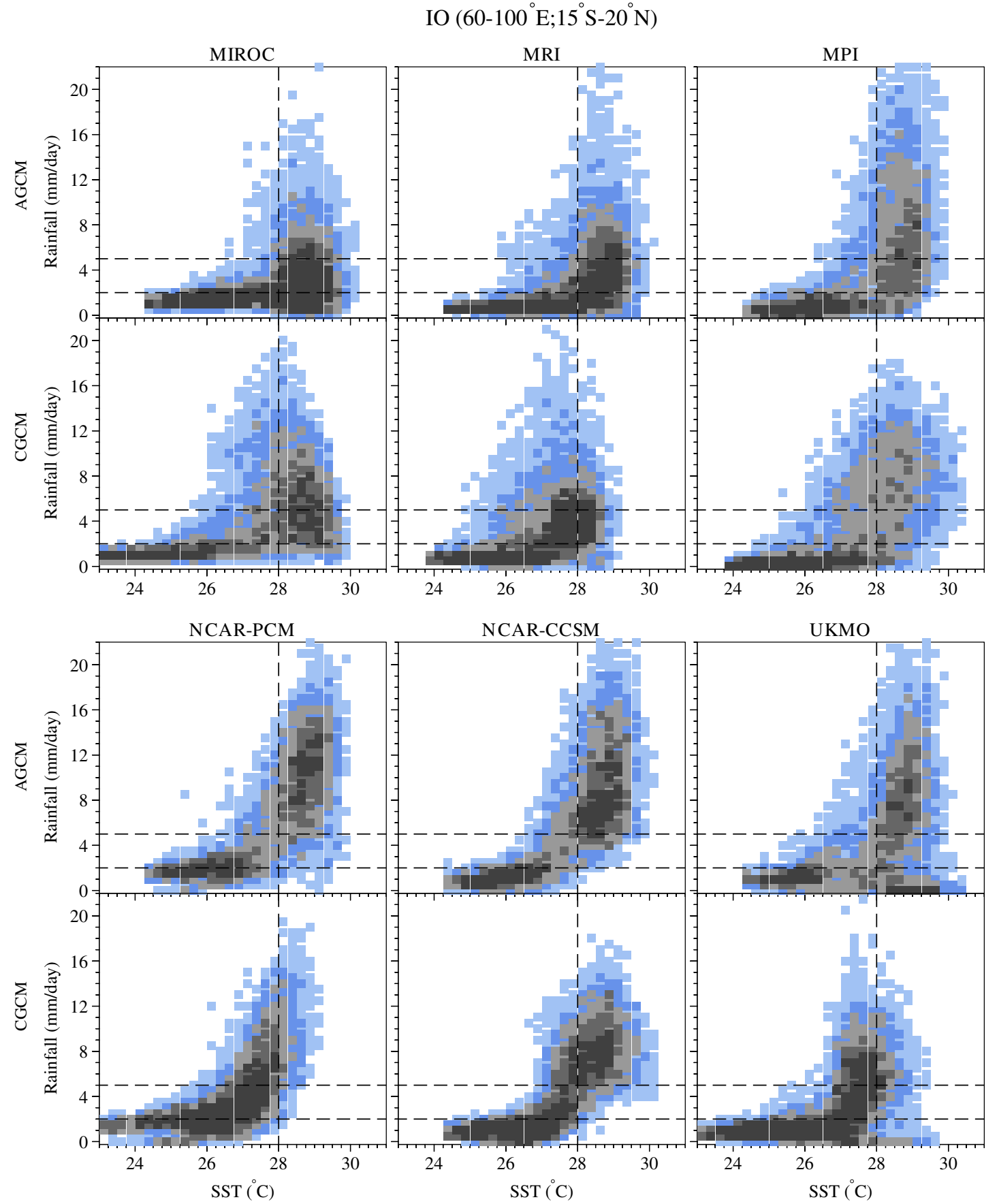

Figure 4. Scatter plots with the number of points in each $0.25^{\circ} \mathrm{C} \mathrm{SST}$ and $0.5 \mathrm{~mm} /$ day rainfall bin from $\mathrm{AGCM}$ and $\mathrm{CGCM}$ simulations of MIROC, MRI, MPI, NCAR-PCM, NCAR-CCSM, and UKMO for the Indian Ocean (IO). 


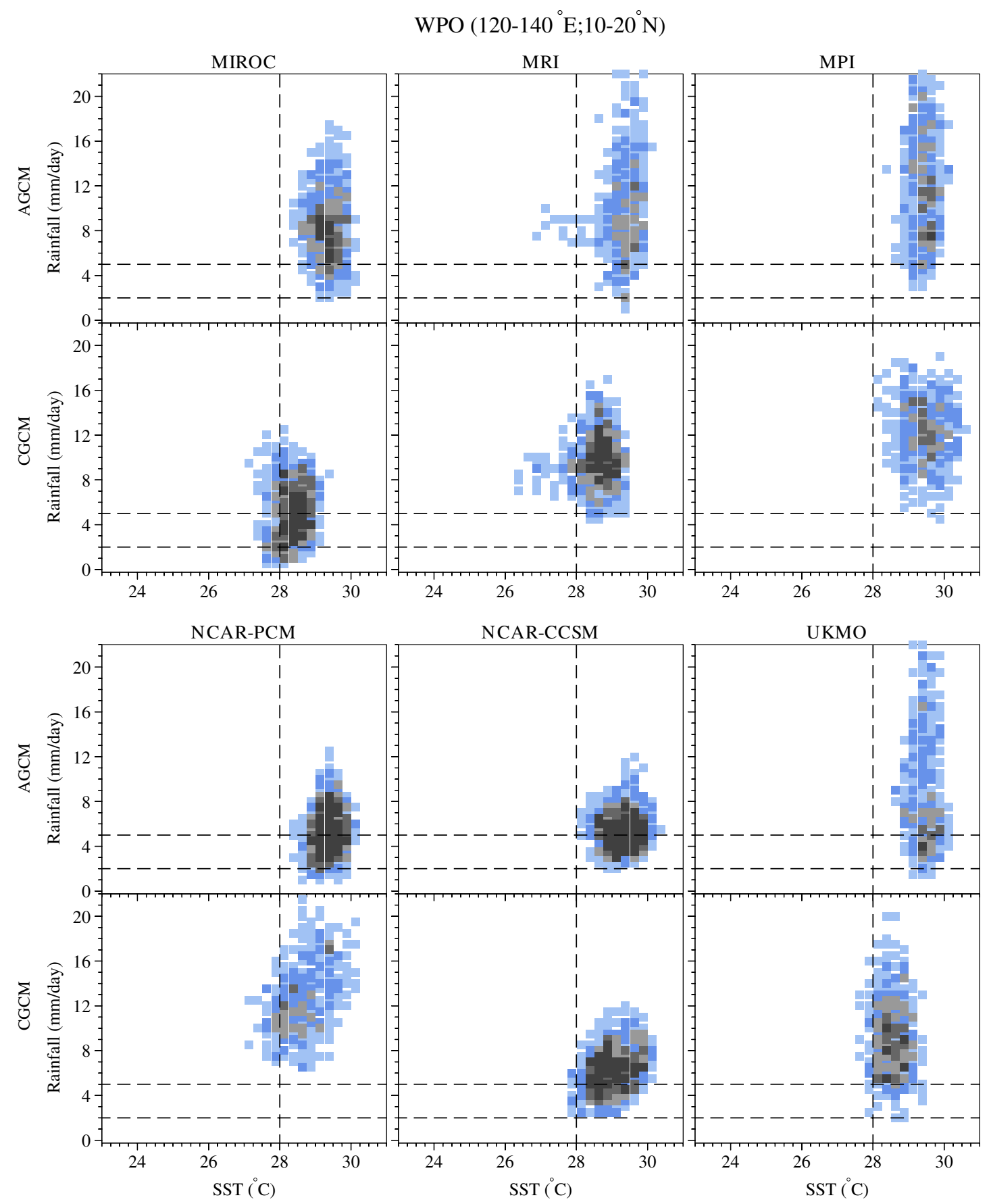

Figure 5. Scatter plots with the number of points in each $0.25^{\circ} \mathrm{C} \mathrm{SST}$ and $0.5 \mathrm{~mm} /$ day rainfall bin from $\mathrm{AGCM}$ and $\mathrm{CGCM}$ simulations of MIROC, MRI, MPI, NCAR-PCM, NCAR-CCSM, and UKMO for the West Pacific Ocean (WPO).

the occurrence of evaporation increases by about $3-$ $4^{\circ} \mathrm{C}$. Johnson and Xie (2010) have shown that the upper tropospheric temperature simulated by coupled models varies with the SST threshold/tropical mean SST. Hence, we expect the simulated upper tropospheric temperature in models with a cold bias in SST to be colder, and hence the moist static instability is larger for a given SST. Consequently, the SST threshold is expected to be lower and the entire SST-rainfall pattern to shift towards colder SST.

\section{Rainfall, SST and convergence}

Thus, an important result of this study is that on the whole, the SST-rainfall relationship over IO and WPO is well simulated by the AGCMs and CGCMs. The CGCMs as a class do not have better skill in simulating this relationship than the AGCMs. Our results differ markedly from the deduction by Wang et al (2004) that AGCMs are unable to reproduce the actual SST-rainfall relationship over the Indo-Pacific oceans which was 


\section{NINO3.4 (170-120 $\left.\mathrm{W} ; 5^{\circ} \mathrm{S}-5^{\circ} \mathrm{N}\right)$}
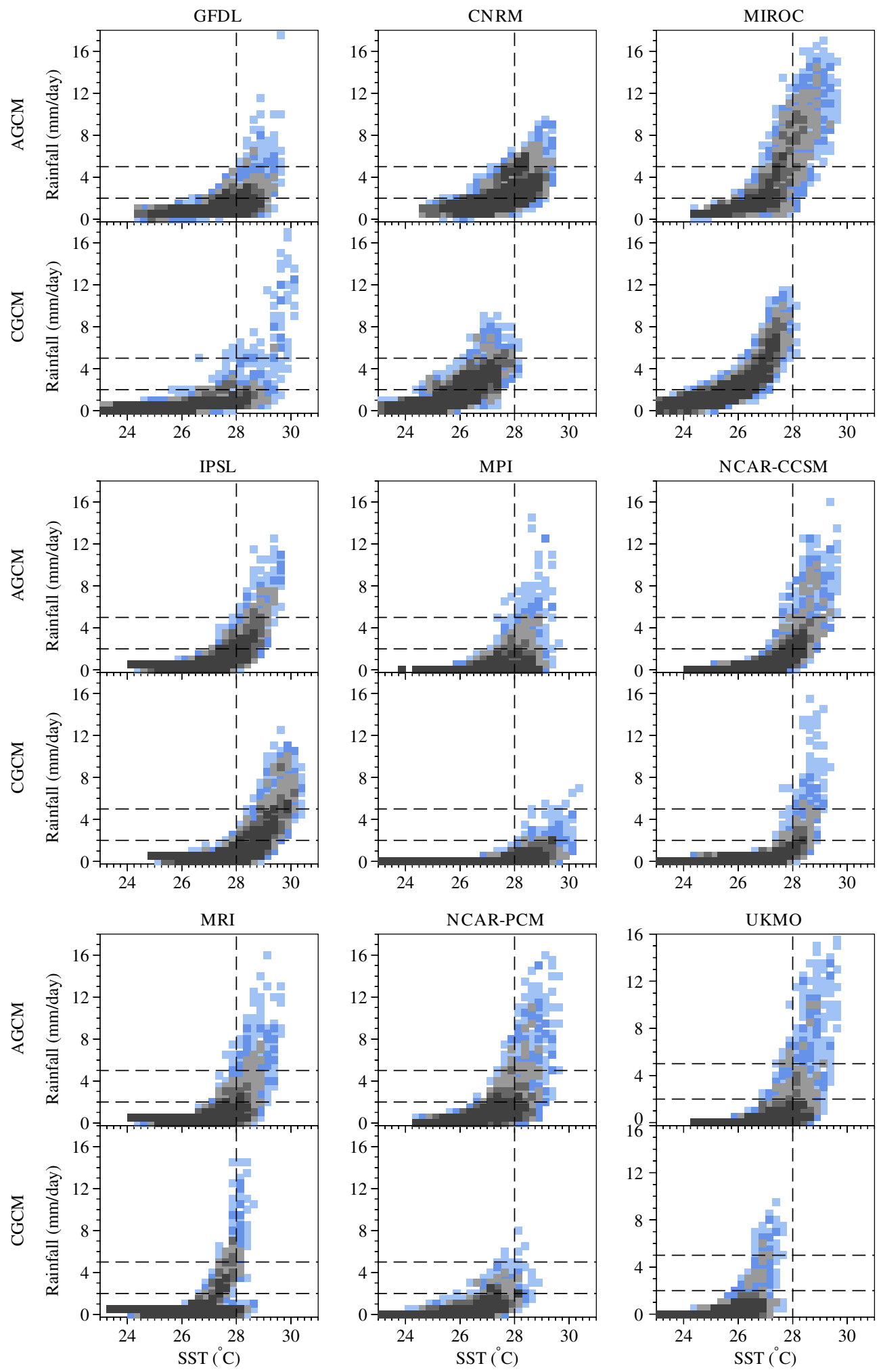

Figure 6. Scatter plots with the number of points in each $0.25^{\circ} \mathrm{C}$ SST and $0.5 \mathrm{~mm} /$ day rainfall bin from AGCM and CGCM simulations of GFDL, CNRM, MIROC, IPSL, MRI, MPI, NCAR-PCM, NCAR-CCSM, and UKMO for NINO3.4 region. 
based on a comparison of the observations and simulations for the most commonly used measure of the SST-rainfall relationship, viz., the correlation (Wang et al 2004, 2005). The observed and simulated correlation of the local SST and rainfall is shown in figures 7 and 8. Wang et al (2005) suggested that the observed negative correlation over warm oceans such as WPO is a consequence of the impact of the atmosphere on SST and therefore can be simulated only by coupled models and cannot be simulated by atmospheric models. However, it is seen that AGCMs do simulate negative correlations (simply because the atmospheric dynamics leads to lower rainfall over warmer SSTs) and not all the coupled models simulate the negative correlation over WPO.

On the whole, the models have reasonable success in simulating the observed pattern of correlation (figures 7 and 8). Almost all the models simulate regions of high positive correlation over central and eastern equatorial Pacific and negative correlation over parts of the tropical West Pacific. Clearly AGCMs are not inherently incapable of simulating negative correlations between rainfall and local SST (figures 7 and 8). However, it is important to note that given the nonlinear nature of the SST-rainfall relationship, a linear measure of the relationship such as the correlation coefficient may not be the appropriate measure because it depends upon the range of the SST considered. Gadgil et al (1984) showed that while the overall correlation between SST and cloudiness for the Indian Ocean during the boreal summer is +0.54 , it drops to +0.18 when only SST above $28^{\circ} \mathrm{C}$ is considered. Graham and Barnett (1987) have pointed out that "One might be tempted to fit a sharp looking curve to the distribution which suggests a strong dependence of convection on SST. However, associations between SSTs and OLR for SSTs above $28^{\circ} \mathrm{C}$ at applicable locations suggest that the dependence of the level of convection in this temperature range is usually slight." Clearly, although SST being sufficiently high is a necessary condition for the occurrence of organized convection/rainfall, it is not a sufficient condition. Hence, when SST is above the threshold $T_{C}$ (such as for WPO), it appears to play no role in determining the variability of convection or rainfall. Graham and Barnett (1987) showed that over warm oceans for which the SSTs are above $T_{C}$, whether there is convection or not depends not on the local SST but on the dynamics, i.e., low level convergence. Bony et al (1997) suggested that intense convection is, in part, a consequence of organized large-scale vertical motion arising from remote forcing.
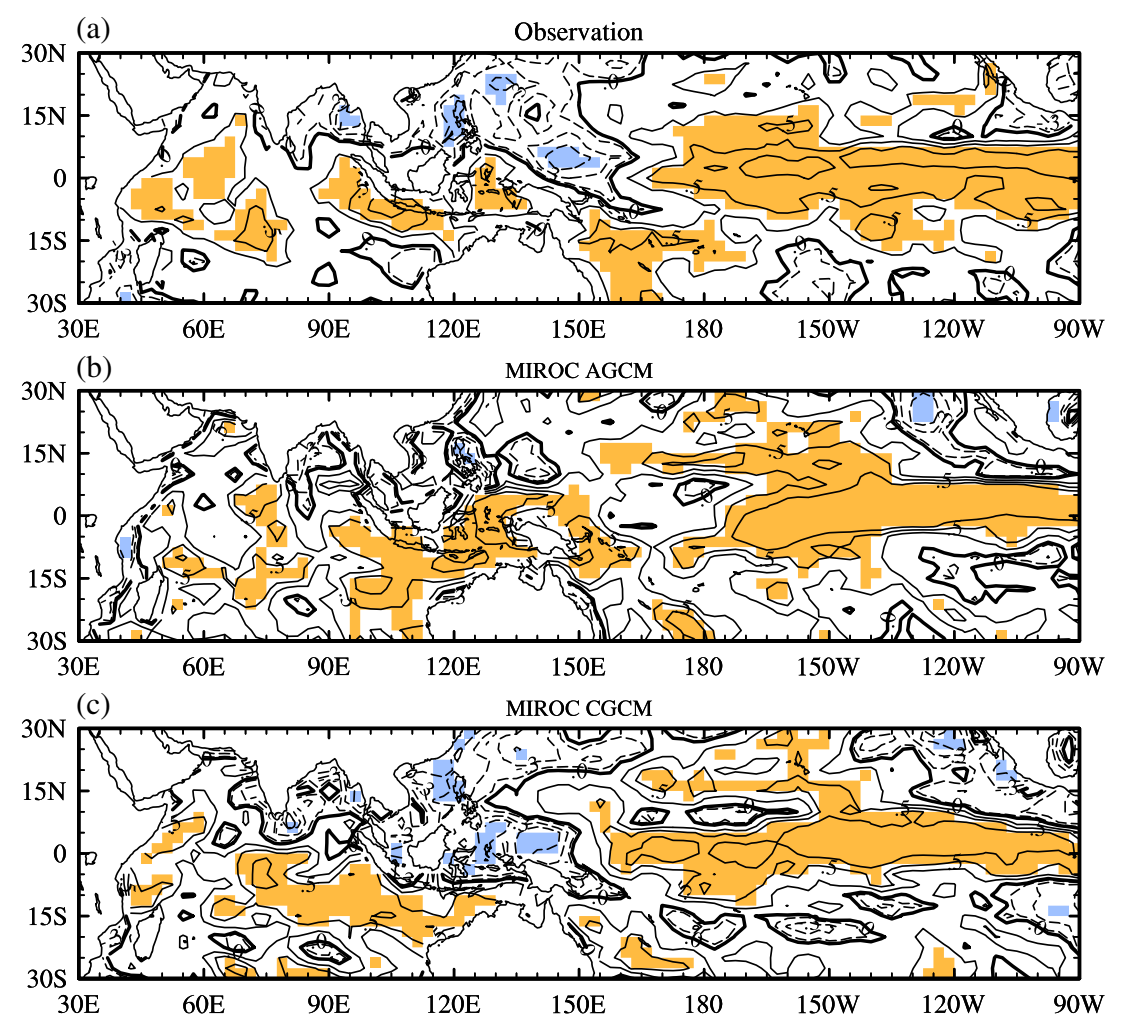

Figure 7. (a) Observed correlation between rainfall (GPCP) and local SST (HadISST) for June-July-August and correlation between the rainfall and local SST from (b) AGCM and (c) corresponding CGCM simulations of MIROC. Regions with correlation significant at $95 \%$ are shaded. 

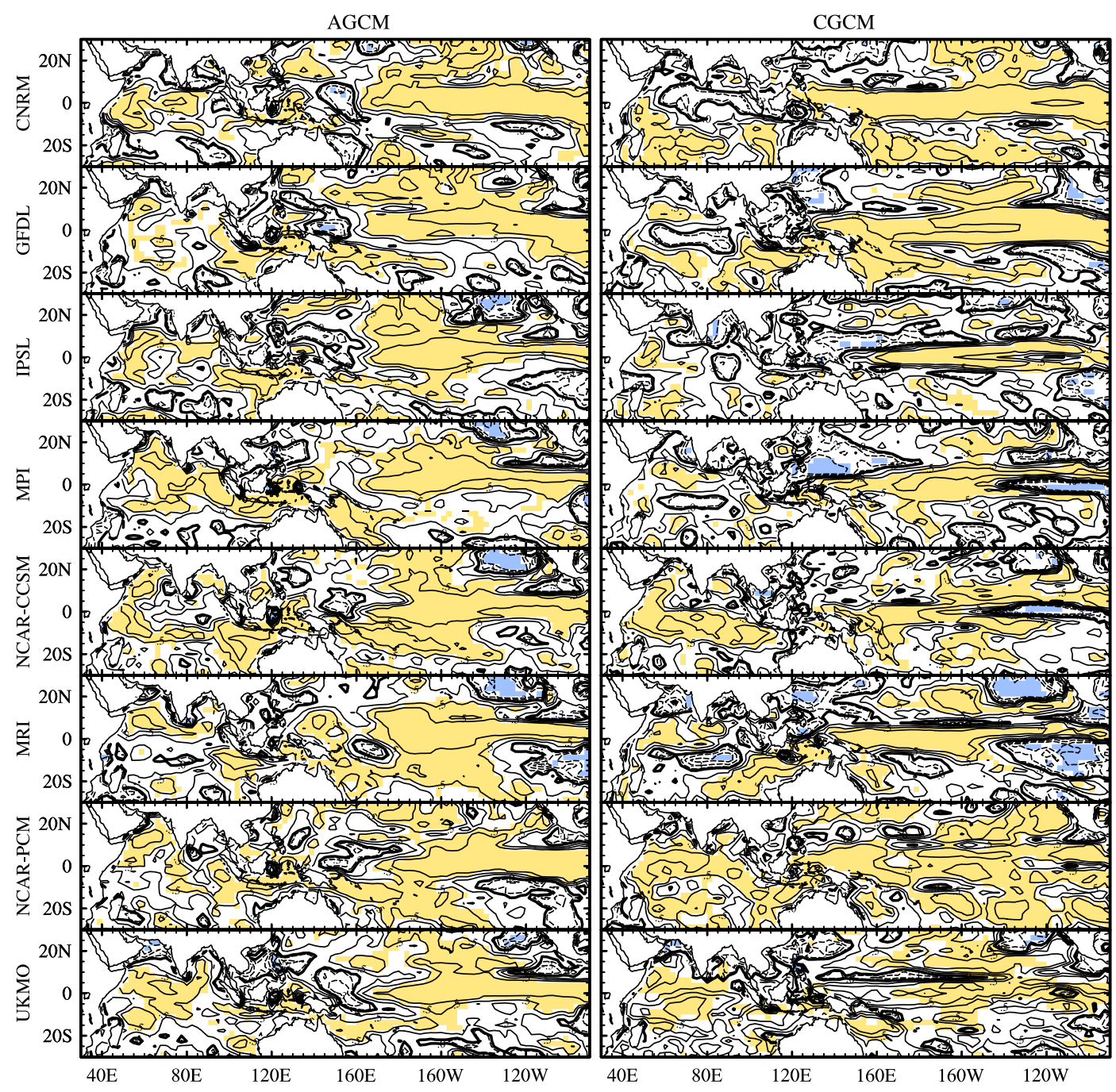

Figure 8. Simulated correlation between rainfall and local SST for June-July-August from AGCM and corresponding CGCM simulations of CNRM, GFDL, IPSL, MPI, NCAR-CCSM, MRI, NCAR-PCM, and UKMO. Regions with correlation significant at $95 \%$ are shaded.

We therefore considered the relationship between SST, rainfall and convergence at $850 \mathrm{hPa}$ (C850) over WPO (figure 9). The relationships in observations and in the simulation by one model (MIROC) are shown in figure 9. We note that while a strong relationship is observed between rainfall and C850, the relationship of convergence/rainfall with SST is much weaker. This supports Graham and Barnett's (1987) conclusion that over regions for which the SST is above $T_{C}$, organized convection is determined by circulation rather than by SST. As pointed out earlier, the AGCM and CGCM versions of all the models are able to simulate the lack of relationship between SST and rainfall over WPO. We find that both versions of several models (e.g., GFDL, MPI and UKMO in figure 10) successfully simulate the strong relationship between the rainfall and C850. However, for some models such as CNRM (figure 10), neither the AGCM nor the CGCM is able to simulate this relationship (figure 10). What leads to this peculiar feature of lack of relationship between $850 \mathrm{hPa}$ convergence and rainfall needs to be investigated. However, it is clear that no CGCM has a better skill in simulation of this relationship than the corresponding AGCM.

\section{Conclusions}

We find that, on the whole, the simulation of the observed nonlinear relationship between SST and rainfall by CGCMs and AGCMs is realistic. The major features of the observed SST-rainfall relationship are: low rainfall over cold regions (with SST less than about $26^{\circ} \mathrm{C}$ ), high propensity of rainfall and a very large spread of rainfall values for SSTs above a threshold $T_{C}$. Thus, while there is a strong relationship between the observed variation of rainfall and SST over the regions for which the 
SST varies across $T_{C}$, over warm oceans for which the SST is always above $T_{C}$, the SST variation does not play any role in determining the observed variation of organized convection/rainfall. We find that all these features are well simulated by the AGCMs and CGCMs. Over warm oceans for which SST is always above the threshold, SST forcing does not play an important role in determining the variability of the rainfall simulated by AGCMs and CGCMs. Furthermore, the nature of the relationship of the simulated rainfall with SST for the atmospheric version of the models is similar to that for the coupled version of the same model, except for a shift to colder/warmer SSTs in case of a cold/warm bias in the coupled version.
Clearly, the coupled models as a class are not superior to the AGCMs in simulating the SST-rainfall relationship.

Thus, if a realistic simulation of this relationship over warm oceans such as WPO is indeed the most crucial factor (Wang et al 2005), we do not expect the coupled models as a class to have an edge over the AGCMs in simulation/prediction of the interannual variability of the monsoon. We believe that these findings have an important implication for dynamical seasonal prediction of the monsoon as they suggest that it may be possible to increase the level of boundary forced predictability through improvement of the AGCMs with further research and development. (i) OBS
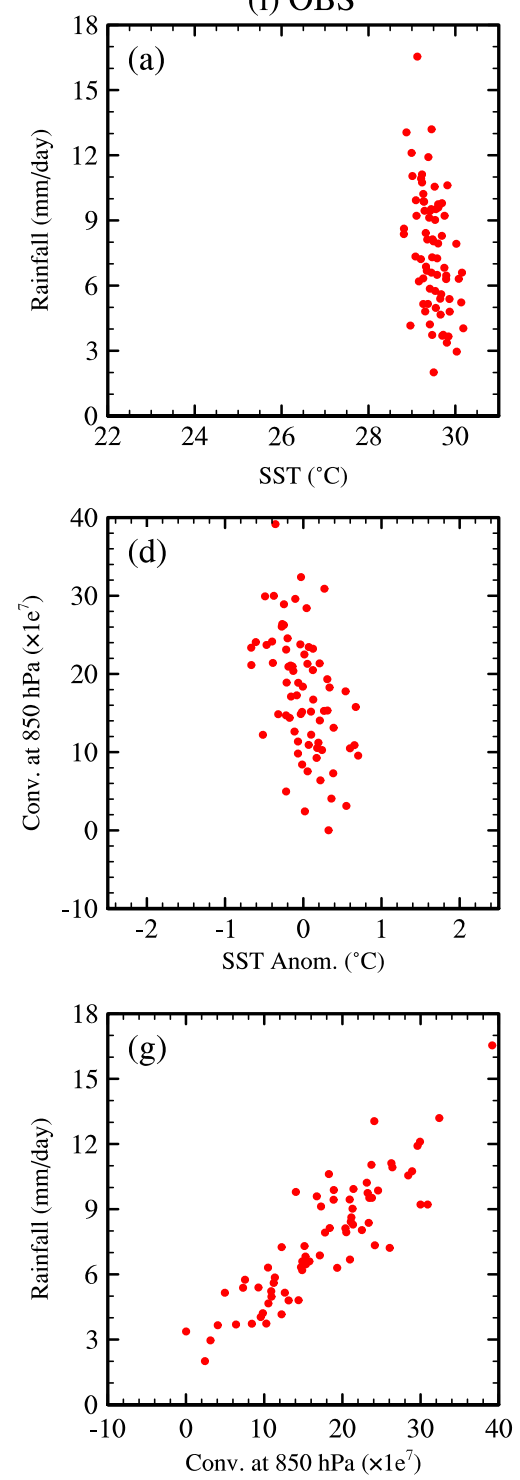

(ii) AGCM
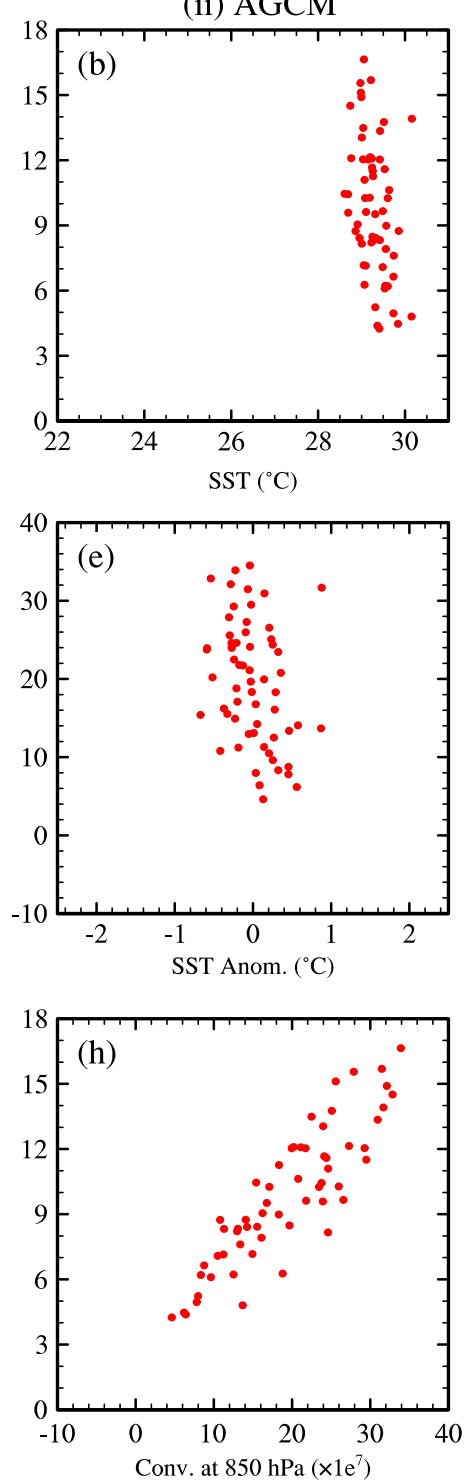

(iii) $\mathrm{CGCM}$
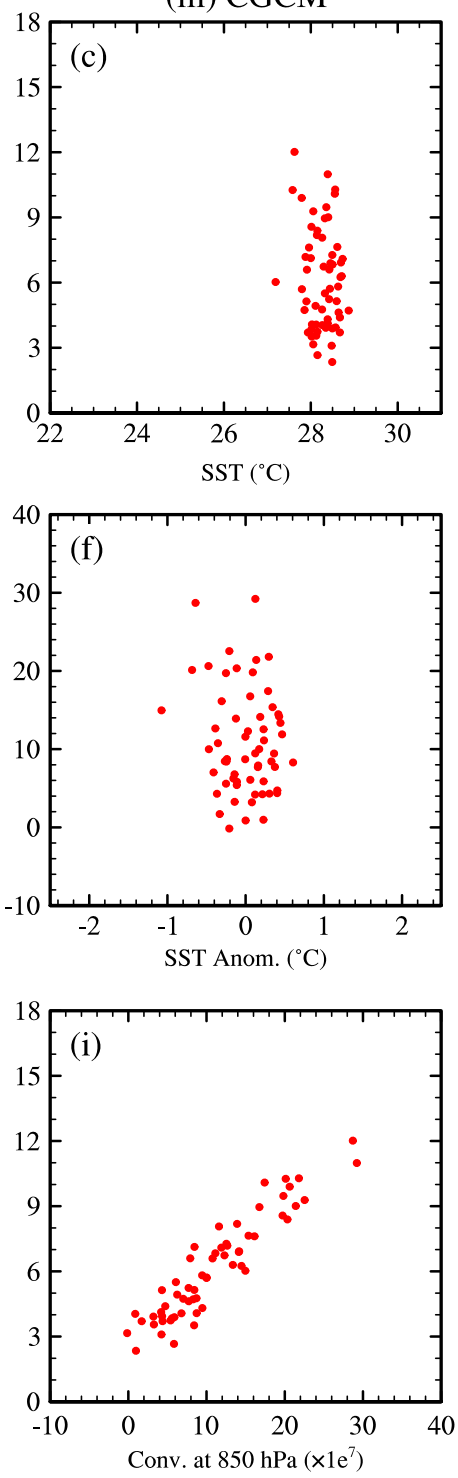

Figure 9. Relationship between (i) SST and rainfall, (ii) SST and convergence at $850 \mathrm{hPa}$ and (iii) between convergence at $850 \mathrm{hPa}$ and rainfall during June, July, and August for the WPO region from observation (a, d, g) and MIROC AGCM $(\mathbf{b}, \mathbf{e}, \mathbf{h})$ and $\operatorname{CGCM}(\mathbf{c}, \mathbf{f}, \mathbf{i})$ simulations. 


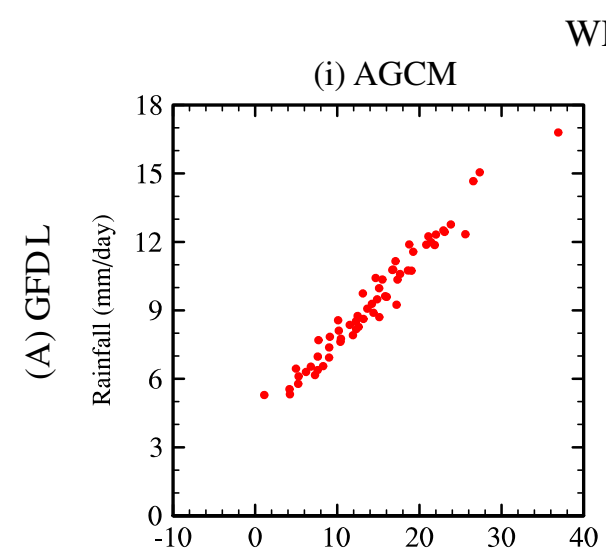

WPO

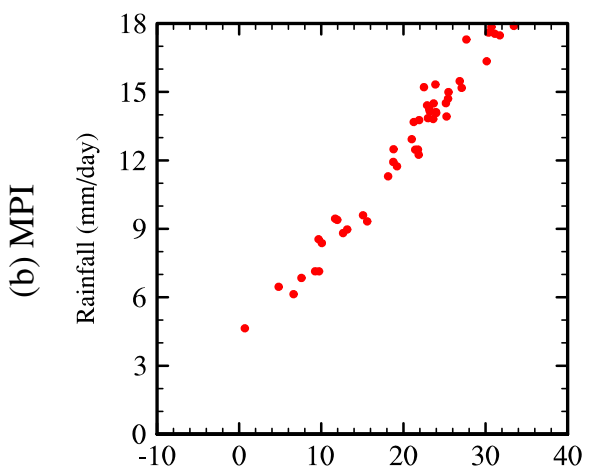

(ii) CGCM
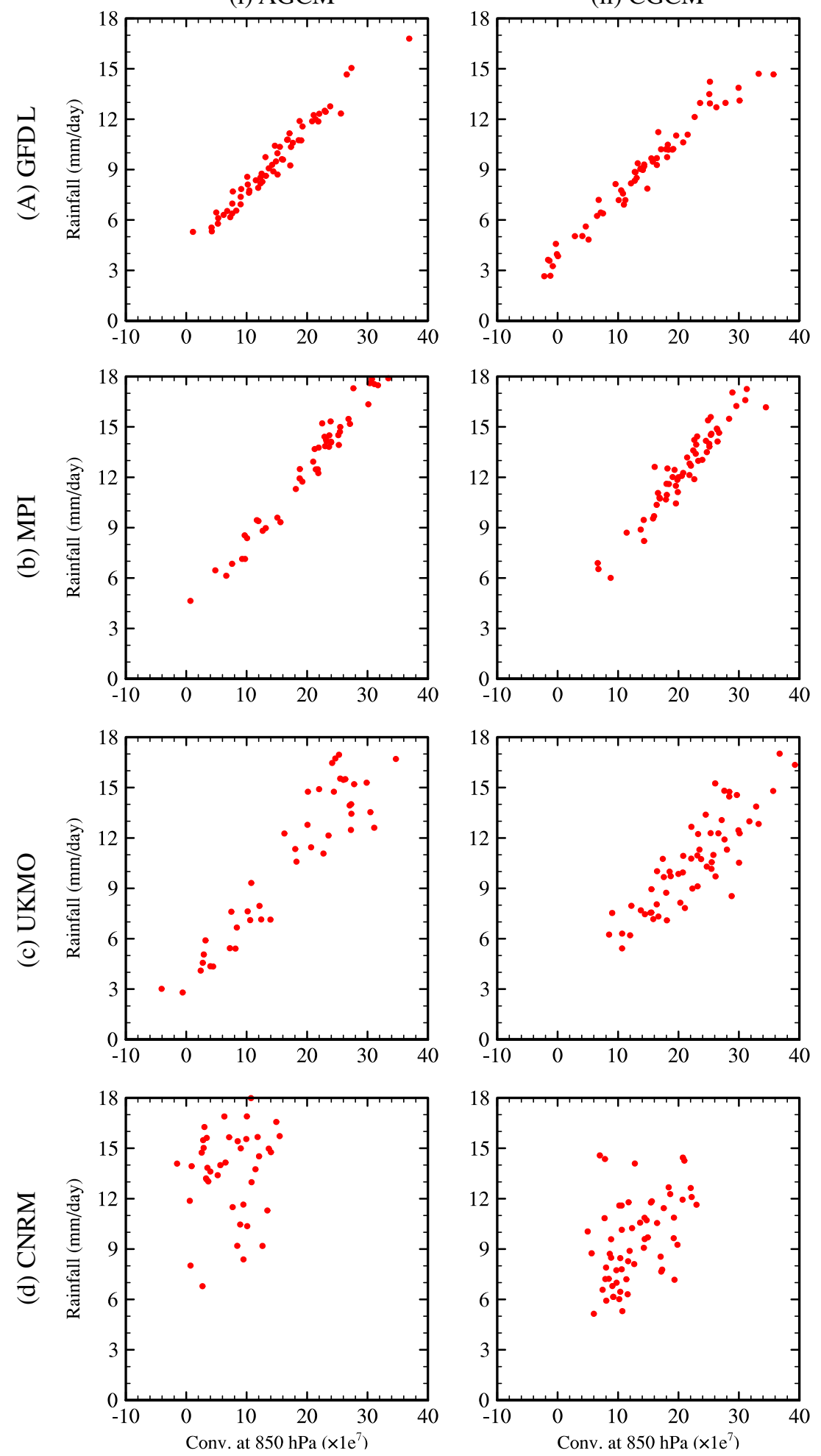

Figure 10. Relationship between convergence at $850 \mathrm{hPa}$ and rainfall during June, July and August for the WPO region from (a) GFDL, (b) MPI, (c) UKMO and (d) CNRM AGCM and CGCM simulations.

\section{Acknowledgements}

It is a pleasure to acknowledge stimulating discussions with Profs. George Philander, Mike Wallace,
Duane Waliser, Mark Cane and Steve Zebiak. We are grateful to the modelling groups and the Program for Climate Model Diagnosis and Intercomparison (PCMDI) for making available the IPCC 
AR4 multimodel dataset. Comments and suggestions provided by the anonymous reviewers have led to substantial improvement in the paper. KR acknowledges the support under research grant from Megha-Tropiques Mission of ISRO. RSN thanks INCOIS for its support. RSN, SG and JS thank Ministry of Earth Sciences (MoES) for the research grant.

\section{References}

Adler R F, Huffman G J, Chang A, Ferraro R, Xie P, Janowiak J, Rudolf R, Schneider U, Curtis S, Bolvin D, Gruber A, Susskind J, Arkin P and Nelkin E 2003 The version 2 Global Precipitation Climatology Project (GPCP) monthly precipitation analyis (1979-present); J. Hydometeor. 4 1147-1167.

Bhat G S, Srinivasan J and Gadgil S 1996 Tropical deep convection, convective available potential energy and sea surface temperature; J. Meteor. Soc. Japan 74 155-166.

Bjerknes J 1969 Atmospheric teleconnections from the Equatorial Pacific; Mon. Weather Rev. 97 163-172.

Bony S, Lau K M and Sud Y C 1997 Sea surface temperature and large-scale circulation influences on tropical greenhouse effect and cloud radiative forcing; J. Climate $\mathbf{1 0}$ 2055-2077.

Bougeault P 1985 A simple parameterization of the largescale effects of cumulus convection; Mon. Weather Rev. $1132108-2121$.

Emanuel K A 1991 A scheme for representing cumulus convection in large-scale models; J. Atmos. Sci. 48 23132329.

Emori S, Nozawa T, Numaguti A and Uno I 2001 Importance of cumulus parameterization for precipitation simulation over East Asia in June; J. Meteor. Soc. Japan 79 939-947.

Gadgil S, Joseph P V and Joshi N V 1984 Oceanatmospheric coupling over monsoon regions; Nature 312 141-143.

Gadgil S and Sajani S 1998 Monsoon precipitation in the AMIP runs; Climate Dyn. 14 659-689.

Gates W L 1992 AMIP: The atmospheric model intercomparison project; Bull. Am. Meteor. Soc. 73 1962-1970.

Graham N E and Barnett T P 1987 Observations of sea surface temperature and convection over tropical oceans; Science 238 657-659.

Gregory D and Rowntree P R 1990 A mass flux convection scheme with representation of cloud ensemble characteristics and stability-dependent closure; Mon. Weather Rev. $1181483-1506$.

Johnson N C and Xie S-P 2010 Changes in the sea surface temperature threshold for convection; Nature Geosci. 3 842-845.

Kang I-S, An S-I and Jin F-F 2001 A systematic approximation of the SST anomaly equation for ENSO; J. Meteor. Soc. Japan 79 1-10.

Kang I-S, Jin K, Wang B, Lau K-M, Shukla J, Krishnamurthy V, Schubert S D, Waliser D E , Stern W F, Kitoh A, Meehl G A, Kanamitsu M, Galin V Y, Sathyan V, Park C-K and Lin Y 2002 Intercomparison of the climatological variation of Asian summer monsoon precipitation simulated by 10 GCMS; Clim. Dyn. 19 383-395.

Kang I-S and Shukla J 2005 Dynamical seasonal prediction and predictability of monsoon; In: The Asian Monsoon (ed.) Wang B (Chichester, UK: Praxis Publ. Ltd.).
Kawamura R, Matsuura T and Iizuka S 2001 Role of equatorial asymmetric sea surface temperature anomalies in the Indian Ocean on the Asian summer monsoon and El Niño-southern oscillation coupling; J. Geophys. Res. 106 4681-4693.

Kumar A and Hoerling M P 1998 Specification of regional sea surface temperatures in atmospheric general circulation model simulations; J. Geophys. Res. 103 8901-8907.

Lau N C and Nath M J 2000 Impact of ENSO on the variability of the Asian-Australian monsoons as simulated in GCM experiments; J. Climate 13 4287-4309.

Lau K-M, Kim K-M and Yang S 2000 Dynamical and boundary forcing characteristics of regional components of the Asian summer monsoon; J. Climate 13 2461-2482.

Meehl G A, Covey C, Delworth T, Latif M, McAvaney B, Mitchell J F B, Stouffer R J and Taylor K E 2007 The WCRP CMIP3 multimodel data set; Bulll. Am. Meteor. Soc. 88 1383-1394.

Moorthi S and Suarez M J 1992 Relaxed Arakawa-Schubert: A parameterization of moist convection for general circulation models; Mon. Weather Rev. 120 978-1002.

Nanjundiah R S, Vidyunmala V and Srinivasan J 2005 On the difference in the seasonal cycle of rainfall over India in the Community Climate System Model (CCSM2) and Community Atmospheric Model (CAM2); Geophys. Res. Lett. 32 L20720.

Nitta T 1987 Convective activities in the tropical western Pacific and their impact on the northern hemisphere summer circulation; J. Meteor. Soc. Japan 65 373-390.

Nordeng T E 1994 Extended versions of the convective parameterization scheme at ECMWF and their impact on the mean and transient activity of the model in the tropics; ECMWF Tech. Memo. 206 European Centre for Medium-Range Weather Forecasts, Reading, United Kingdom, 41p.

Palmen E 1948 On the formation and structure of tropical hurricanes; Geophysica 3 26-38.

Pan D-M and Randall D A 1998 A cumulus parameterization with a prognostic closure; Quart. J. Roy. Meteor. Soc. $124949-981$.

Pierrehumbert R T 1995 Thermostats, radiator fins, and the local runaway greenhouse; J. Atmos. Sci. 52 17841806.

Ramanathan V and Collins W 1991 Thermodynamic regulation of ocean warming by cirrus clouds deduced from observations of the 1987 El-Nino; Nature 351 27-32.

Rasmusson E M and Carpenter T H 1983 The relationship between eastern equatorial Pacific sea surface temperature and rainfall over India and Sri Lanka; Mon. Weather Rev. $111517-528$.

Rayner N A, Parker D E, Horton E B, Folland C K, Alexander L V, Rowell D P, Kent E C and Kaplan A 2003 Global analyses of SST, sea ice and night marine air temperature since the late nineteenth century; J. Geophys. Res. 108, doi: 10.1029/2002JD002670.

Shen S and Lau K-M 1995 Bienniel oscillation associated with the East Asian summer monsoon and tropical sea surface temperatures; J. Meteor. Soc. Japan $\mathbf{7 3}$ $105-124$.

Sikka D R 1980 Some aspects of the large-scale fluctuations of summer monsoon rainfall over India in relation to fluctuations in the planetary and regional scale circulation parameters; Proc. Indian Acad. Sci. (Earth Planet. Sci.) 89 179-195.

Sperber K R and Palmer T N 1996 Interannual tropical rainfall variability in general circulation model simulations associated with the Atmospheric Model Intercomparison Project; J. Climate 9 2727-2750. 
Stone P H and Carlson J H 1979 Atmospheric lapse rate regimes and their parameterization; J. Atmos. Sci. 36 415-423.

Stowasser M, Annamalai H and Hafner J 2009 Response of the south Asian summer monsoon to global warming: mean and synoptic systems; J. Climate 22 1014-1036.

Tiedtke M 1989 A comprehensive mass flux scheme for cumulus parameterization in large-scale models; Mon. Weather Rev. 117 1779-1800.

Tokioka T, Yamazaki K, Kitoh A and Ose T 1988 The equatorial 30-60-day oscillation and the Arakawa-Schubert penetrative cumulus parameterization; J. Meteor. Soc. Japan 66 883-901.

Trenberth K E and Shea D-J 2005 Relationships between precipitation and surface temperature; Geophys. Res. Lett. 32 L14703, doi: 10.1029/2005GL022760.

Uppala S M, Kallberg P W, Simmons A J, Da Costa A U, Bechtold V, Fiorino M, Gibson J K, Haseler J, Hernandez A, Kelly G A, Li X, Onogi K, Saarinen S, Sokka N, Allan R P, Andersson E, Arpe K, Balmaseda M A, Beljaars A C M, Van De Berg L, Bidlot J, Bormann N, Caires S, Chevallier F, Dethof A, Dragosavac M, Fisher M, Fuentes M, Hagemann S, Holm E, Hoskins B J, Isaksen L, Janssen P A E M, Jenne R, McNally A P, Mahfouf J-F, Morcrette J-J, Rayner N A, Saunders R W, Simon P, Sterl A,
Trenberth K E, Untch A, Vasiljevic D, Viterbo P and Woolen J 2005 The ERA-40 reanalysis; Quart. J. Roy. Meteor. Soc. 131 2961-3012.

Waliser D E and Graham N E 1993 Convective cloud system and warm pool sea-surface temperature: coupled interaction and self regulation; J. Geophys. Res. 98 $12,881-12,893$.

Wang B, Kang I-S and Lee J-Y 2004 Ensemble simulations of Asian-Australian monsoon variability by 11 AGCMs; J. Climate 17 803-818.

Wang B, Ding Q, Fu X, Kang I-S, Jin K, Shukla J and Doblas-Reyes F 2005 Fundamental challenge in simulation and prediction of summer monsoon rainfall; Geophys. Res. Lett. 32 L15711, doi: 10.1029/2005G1022734.

Williams E and Renno N 1993 An analysis of the conditional instability of the tropical atmosphere; Mon. Weather Rev. $12121-36$.

Wu R and Kirtman B P 2005 Roles of Indian and Pacific Ocean air-sea coupling in tropical atmospheric variability; Clim. Dyn. 25 155-170.

Zhang C 1993 Large-scale variability of atmospheric deep convection in relation to sea surface temperature in the tropics; J. Climate 6 1898-1912.

Zhang G J and McFarlane N A 1995 Sensitivity of climate simulations to the parameterization of cumulus convection in the CCC-GCM; Atmos.-Ocean 3 407-446. 